\title{
The Surgical Treatment of the Anal Stricture Post Hemorrhoidectomy Milligan-Morgan. A Comparison of Two Operatory Techniques
}

\author{
Enton Bollano PhD ${ }^{1}$, Krenar Lilaj PhD ${ }^{2}$, Dariel Thereska PhD $^{3}$, Arben Gjata ${ }^{4}$ \\ ${ }^{1,3}$ QSUT, Surgeon \\ ${ }^{2}$ QSUT, Anesthesiologist \\ ${ }^{4}$ Professor, QSUT, Surgeon
}

\begin{abstract}
Surgical treatment of anal stricture in open posthemorrhoidectomy brings various complications to the open hemorrhoidectomy in 5\%-10\% of the cases. In books it is widely known as "the fibrotic benign stricture" or as "iatrogenic stricture". Clinically, it is manifested with pain during defecation, minimal rectoragy and abdominal discomfort accompanied with a feeling of not having adequately emptied the bowels. Locally, it is manifested in the form of a rigid ring where even the small finger can hardly be penetrated. These symptoms can severely affect the quality of life in patients. Depending on the grade of the anal canal stricture, we can say that the anal stricture is found on three grades: light anal stricture, moderated anal stricture and expressed anal stricture. All our patients resulted in expressed anal stricture. In our research we have compared two operative techniques which were applied for the surgical treatment of the pathology. Partial posterior internal sphincterotomy technique with anoplastic in the open wound (SIPA) and the plastic with skin flap and closed internal lateral sphincterotomy, $V-Y$ advancement flap (PLSL). Each technique aims at relaxing the anal canal with as less continence damage as possible and faster rehabilitation of the patient. The patients were divided into two groups: Group A of 15 patients treated with the SIPA technique and Group B of 14 patients treated with the PLSL technique. The study was conducted during February 2006 - March 2014. The results favored the PLSL technique.
\end{abstract}

Keywords: surgical treatment anal stricture post hemorrhoidectomy Milligan-Morgan

\section{Patients and Method}

This research summarizes the results of the surgical treatment in 29 patients diagnosed in open posthemorrhoidectomy anal stricture. The study was conducted during February 2006 - March 2014. Average age resulted: 47.21 year old (36-64 years old). The patients were called in for a visit after approximately 64.6 days (4578 days) after the first intervention. The second intervention was conducted within ten days from submission. It was performed with spinal anesthesia, by injecting $2 \mathrm{ml}$ lidocain solution, $2 \%$ in the intervertebral area L3-L4. Before surgery all patients had the routine tests done, were evaluated about the accompanying pathologies and were performed an anoscopy with pediatric anoscope (HillFerguson) (1.5). Preoperative preparation consisted in light hydric diet for two days before surgery and four microclismas four and two hours before surgery. The A Technique consists in posterior excision of mucotaneous area approximately $0.5 \mathrm{~cm}$ along the circumference of the stricture ring. The intraanal excision extends to the Morgan crypt level, whereas the perianal excision approximately 0.5 $\mathrm{cm}$ from the anal margo. The excised material has the form of a trapezium. Later, a partial internal posterior sphincterotomy at the crypt level is performed. The last phase consists in fixing the anal mucous above the internal anal muscle with special vicruly sutures $3-0$. Not more than four sutures. The wound below the suture's line is left open. The B Technique consists in deep posterior intraanal linear incision at six o'clock, up to the level of Morgan crypts. The wound comes in the form of " $\mathrm{V}$ ". Then the incision extends in the perianal area, thus forming a "leather triangle" (a skin flap in the form of a triangle). The triangle legs must have almost the same length of the intraanal incision $(3,5,9,10)$. Then, the triangular skin flap moves along with the subcutaneous fat tissue (to maintain regular blood supply in the skin flap) and is fixed at the intraanal incision spot. For fixing the skin flap in the intraanal area we use special 3-0 vicryl sutures $(2,7,9)$. In the end, a left lateral intern sphincterotomy with a round edge lancet (no. 15) is performed. The last stage of the surgery is the suturation of the perianal wound. Two are the key moments in this technique: 1) avoid tension during skin flap fixing and: 2) optimal blood supply in the skin flap. We have chosen the posterior part for performing this technique due to the fact that there were no manipulations in this area in the previous intervention. In both techniques we put perianal swab gauze, because intraanaly we have applied $5 \mathrm{ml}$ of lidocaine gel, 2 $\%$.

Accompanying diseases resulted in: three patients suffered of HTA, stabilized under therapy; one patient was diagnosed with acalculous cholecystitis and; one patient was operated long ago of dexter inguinal hernia.

None of the patients suffered of inflamatory pathologies of the colon or any kind of malign pathology. Most of the patients (25 in all) had undergone colonoscopy before the first intervention (hemorrhoidectomy).

\section{Post Operative Follow Up}

Pain relief after surgery consisted in the application of a hydrochloride morphine ampoule of $10 \mathrm{mg} \mathrm{/} \mathrm{ml}$ 


\section{International Journal of Science and Research (IJSR) \\ ISSN (Online): 2319-7064}

Index Copernicus Value (2013): 6.14 | Impact Factor (2015): 6.391

subcutaneously when the anesthesia wears off. Postoperative patients were treated with 1.5 liters of physiological intravenous and an antibiotic, 2.0 intravenous ampicilin divided into three doses. Hydric diet was recommended for the first 10 days after surgery. Mouth feeding starts after the spinal anesthesia wears off. Immediately after starting eating, a laxative is recommended. We recommend a lactulose dose of $5 \mathrm{ml}$, three times a day after each meal, until the first defecation. All patients had their first defecation in the hospital. The patients were discharged only if they did not have postoperative complications. Before discharging, the patients were recommended hydric diets, potassium permanganate wash twice a day and $200 \mathrm{mg}$ Ibuprofen (orally) for the pain. The first follow up visit was made 10 days after the intervention and continued for three months depending on the local state of the surgery wound.

\section{During the research we evaluated:}

- Long and short term postoperative complications

- Hospitalization period

- The level of postoperative pain according to the VAS grade.

- Surgery wound healing

- Anal incontinence evaluation three months after the intervention

- Patients complaints three months after the intervention

Quick complications were evaluated during hospitalization, short term complications, up to the tenth day, and long term complications, after the tenth day. Hospitalization is calculated in days and includes the time from the moment of intervention until discharging of the patient. Tables below show an average value for each group. Postoperative pain is evaluated based on the Visual Analogue Scale (VSA) $(5,12$, 14). The patient is asked to give a pain level from 1 to 10 where number 1 indicates very slight pain and 10 the severest, unbearable pain. Pain level in our research has been evaluated during the act of defecation, during the hospitalization period, 10 days after the intervention and then again, three months after the intervention. The tables also give an average value for each group. The time of operative wound healing starts at the moment of intervention until full epithalialization of the surgery wound. Three months after the intervention we also evaluated patients complaints related to the intervention.

\section{Statistic Analysis}

Data analysis was performed by means of Statistic Package SPSS 20.0 (Statistical Package for Social Sciences). Absolute numbers and respective percentages were calculated for all categorical (nominal include binary/dichotomy and ordinal) variables. For all numeric variables, when the data underwent normal expansion, respective standard arithmetic \pm deviations were calculated. Differences of discreet variables between the groups were performed by means of Hi-katror tests. Differences of quantitative variables between the groups were performed by the student test. $\mathrm{p} \leq 0.05$ values were considered significant.

\section{Results}

Immediate postoperative complications (during hospitalization period)

\begin{tabular}{|c|c|c|c|c|}
\hline No & Complications / Group & $\begin{array}{c}\text { Group A } \\
(n=15)\end{array}$ & $\begin{array}{c}\text { Group B } \\
(n=14)\end{array}$ & $\begin{array}{c}\text { Value } \\
p^{*}\end{array}$ \\
\hline 1 & Rectoragy & $4(26.6)$ & $0(0.0)$ & 0.057 \\
\hline 2 & Urinary retention & $6(40.0)$ & $1(7.1)$ & 0.049 \\
\hline 3 & Hematoma of the surgery wound & $0(0.0)$ & $2(14.2)$ & 0.259 \\
\hline
\end{tabular}

\section{*Hi-katror}

There is a statistically significant difference between the groups $(p=0.049)$, regarding the presence of urinary retention: it is more expressive in group A (40.0\%) and only $1.7 \%$ in group $\mathrm{B}$.

Early postoperative complications (up to the tenth day)

\begin{tabular}{|c|c|c|c|c|}
\hline No & Complications / Group & $\begin{array}{c}\text { Group A } \\
(\mathrm{n}=15)\end{array}$ & $\begin{array}{c}\text { Group B } \\
(\mathrm{n}=14)\end{array}$ & $\begin{array}{c}\text { Value } \\
\mathrm{p}^{*}\end{array}$ \\
\hline 1 & Rectoragy & $3(20.0)$ & $2(14.2)$ & 0.535 \\
\hline 2 & Disuric fenomena & $2(13.3)$ & $0(0.0)$ & 0.259 \\
\hline 3 & Partial skin flap necrosis & $0(0.0)$ & $2(14.2)$ & 0.259 \\
\hline 4 & Hemorrhoidal thrombosis & $2(13.3)$ & $0(0.0)$ & 0.259 \\
\hline
\end{tabular}

*Hi-katror

No significant differences between the groups were observed as far as late postoperative complications are concerned.

Late postoperative complications (after the tenth day)

\begin{tabular}{|c|c|c|c|c|}
\hline No & Complications / Group & $\begin{array}{c}\text { Group A } \\
(\mathrm{n}=15)\end{array}$ & $\begin{array}{c}\text { Group B } \\
(\mathrm{n}=14)\end{array}$ & $\begin{array}{c}\text { Value } \\
\mathrm{p}^{*}\end{array}$ \\
\hline 1 & Rectoragy & $2(13.3)$ & $2(14.2)$ & 0.674 \\
\hline 2 & Disuric fenomena & $2(13.3)$ & $0(0.0)$ & 0.259 \\
\hline 3 & Anal itching & $4(26.7)$ & $0(0.0)$ & 0.057 \\
\hline 4 & Coccydynia & $3(20.0)$ & $0(0.0)$ & 0.125 \\
\hline 5 & Perianal dermatitis & $7(46.7)$ & $0(0.0)$ & 0.004 \\
\hline
\end{tabular}

*Hi-katror

As per late postoperative complications, we notice a statistically significant difference between the groups $(\mathrm{p}=0.004)$, which consists in the manifestation of a perianal dermatitis; it is present in group A (46.7\%), but not in group B.

Hospitalization period (hours)

\begin{tabular}{|l|l|c|c|}
\hline & Group/ hospitalization period & Hours & Value p * \\
\hline 1 & Group A & $39.2 \pm 3.3$ & 0.003 \\
\hline 2 & Group B & $27.4 \pm 2.7$ & \\
\hline
\end{tabular}

*t-test

There is a statistically significant difference in the average hospitalization period between the two groups $(\mathrm{p}=0.003)$.

The patients treated with B Technique have a shorter stay at hospital then patients of group A (39. $2 \pm 3.3$ hours $v s 27$. $4 \pm 2.7$ hours). 


\section{International Journal of Science and Research (IJSR) \\ ISSN (Online): 2319-7064}

Index Copernicus Value (2013): 6.14 | Impact Factor (2015): 6.391

Average level of postoperative pain according VSA

\begin{tabular}{|c|c|c|c|c|}
\hline $\mathrm{No}$ & $\begin{array}{c}\text { Group/ } \\
\text { Average } \\
\text { level of pain } \\
\text { according } \\
\text { VSA }\end{array}$ & $\begin{array}{c}\text { Pain level } \\
\text { (during } \\
\text { hospitalization } \\
\text { period) }\end{array}$ & $\begin{array}{c}\text { Pain level } \\
\text { (after been } \\
\text { discharged: } \\
\text { up to the tenth } \\
\text { day) }\end{array}$ & $\begin{array}{c}\text { Pain level (three } \\
\text { months after the } \\
\text { intervention) }\end{array}$ \\
\hline 1 & Group A & $8.09 \pm 2.1$ & $7.08 \pm 1.7$ & $3.7 \pm 1.0$ \\
\hline 2 & Group B & $6.02 \pm 1.4$ & $4.01 \pm 0.7$ & $1.0 \pm 0.6$ \\
\hline & Value p* & 0.047 & 0.034 & 0.034 \\
\hline
\end{tabular}

*t-test

There is a statistically significant difference in the average pain level according VSA between the two groups. Patients treated with B Technique have a lower average of pain level compared to the patients of group A.

Average value of surgery wound healing time (in days)

\begin{tabular}{|c|c|c|c|}
\hline No & $\begin{array}{c}\text { Group / surgery wound } \\
\text { healing time }\end{array}$ & Days & Value p* \\
\hline 1 & Group A & $24.66 \pm 5.08$ & $<0.001$ \\
\hline 2 & Group B & $14.21 \pm 2.6$ & \\
\hline
\end{tabular}

*t-test

The patients treated with PLSL Technique resulted in faster surgery wound healing, $\mathrm{p}<0.001$ faster, compared to the patients of group A (24.66 \pm 5.08 vs $14.21 \pm 2.6)$.

\section{Incontinency evaluation three months after the intervention}

\begin{tabular}{|c|c|c|c|c|}
\hline No & $\begin{array}{c}\text { Incontinency } \\
\text { type/Group }\end{array}$ & $\begin{array}{c}\text { Group A } \\
(\mathrm{n}=15)\end{array}$ & $\begin{array}{c}\text { Group B } \\
(\mathrm{n}=14)\end{array}$ & $\begin{array}{c}\text { Value } \\
\mathrm{p}^{*}\end{array}$ \\
\hline 1 & Solid faeces & $0(0.0)$ & $0(0.0)$ & na \\
\hline 2 & Liquid faeces and gases & $2(13.3)$ & $0(0.0)$ & 0.259 \\
\hline 3 & Only gases & $3(20.0)$ & $1(7.1)$ & 0.326 \\
\hline
\end{tabular}

*Hi-katror

The Incontinence evaluation three months after the intervention showed no significant differences between the groups.

Three months after the intervention five patients from Group A complained about pains at the level of the surgery wound, of which only one was diagnosed with a "fissure syndrome" because it was related to the defecation act, but no local anal fissure was observed. The patient was immediately treated with the rectal cream nifedipine $0.3 \%$ and lidocaine $1.5 \%$. Four other patients complained of coccygeal pain apart from defecation act and we started a treatment with oral ibuprofen. Only one patient from Group B complained of anterior anal canal out and during defecation.

\section{Discussion}

The technique of fixing the intraanal cutaneous skin flap also known in books as "V-Y advancement flap" was initially applied in our clinic in 2000 . The routine technique applied for the benign anal stricture, was posterior sphincterotomy with anoplastics. According to the results it is evident that the PLSL technique predominates. Early complications are dominated by rectoragy and disuric fenomena, as a result of the open wound and the high level of postoperative pain caused by the SIPA technique. Rectoragy was in low levels and was stopped with swabs, whereas the hematoma at the level of skin flap fixing was evident in the cases of two patients intervened with the PLSL technique. Both patients needed no surgery, even though on the eighth and ninth day partial necroses in the distal part of the skin flap was observed. This area was also the cause of low rectoragy that lasted up to the $16^{\text {th }}$ day in those patients.

In two patients a painful perianal hemorrhoidaltromb was found in the lateral borders of the anoplastics. The statistical difference between the two groups that experienced similar complications was negligible.Late complications observed in Group A are directly connected to the presence of an open wound in a very sensitive area. The perianal pruritus and dermatitis are a consequence of the secretions caused by the operatory wound. The pruritus and perianal dermatitis in the 4 patients was eliminated after the epithalialization of the operatory wound. The perianal dermatitis was found in seven patients. For these patients an additional local treatment with gentamicin sulfat $0.1 \%$ was applied, after consulting a dermatologist. The closing of the operatory wound and local treatment caused the elimination of the dermatitis. Coccydynia is a result of the operatory wound being located in the posterior part of the anal canal as well as close to the coccygeal bone. The statistical results show a significant difference between the two groups, favoring the PLSL technique. The patients who were treated with the PLSL technique spent less time in the hospital. The difference is again statistically significant. This result is a consequence of the fewer postoperatory complications caused by the operatory technique. This knowledge leads to faster rehabilitation for the patient, as well as lower treatment costs. The patients of group A having had more complications, open wounds, and higher pain intensity causing delayed defecation, have stayed for a longer period of time in the hospital compared to the patients of group B. The difference between the two groups in the pain levels during defecation shows the advantage of the PLSL technique. The patients of group B managed to more easily endure the surgery, having experienced less pain. Many of them reported that they were prepared to share their experience with other patientswho suffered from this pathology. In the results of the analysis it is clear that the pain levels have decreased continuously up to the third month. It should be noted that there are still patients of group A who complain about pain. The average value of 3.7 speaks clearly for decrease in the quality of life of the patients. Knowing that the casues of the pain are the ischemy and necrosis and that their levels are directly proportional, the above mentioned difference in pain levels is understandable. In Group A patients the wound was epithalized averagely after 24.66 days compared to the 14.21 days of Group B patients. The cause of the delay in wound healing at patients of Group A is thought to be the surgery technique. The technique has three faults related to the epithalialization of the postoperative wound: 1) The open wound; 2) Posterior sphincterotomy in an area with low blood supply; 3) Anal mucosis fixture with sutures above the anal intern muscle causes local micronecroses. All the above mentioned speak of a high traumatic level of the technique $(4,8)$. Likewise, the level of the postoperative pain differs between the two groups of patients, respectively $8.09-6$. 02. This data solidifies the above mentioned conclusion concerning the traumatic effect of the SIPA technique.

\section{Volume 5 Issue 7, July 2016 www.ijsr.net}




\section{International Journal of Science and Research (IJSR) \\ ISSN (Online): 2319-7064}

Index Copernicus Value (2013): 6.14 | Impact Factor (2015): 6.391

Knowing that the causes of pain are ischemia and necroses and that its level is in right proportion with both these elements, the difference in the pain level given above is more than understandable. We have to emphasize the positive effect of the closed left internal sphincterotomy (1, 3 ). I think that it corrects most of the consequences of the open technique. Normally we do not have to forget the positive effect of the plastic in the skin flap. Hospitalization period makes the difference again: Group A patients, being those who showed more complications: open wound, higher pain level and as a consequence even delayed defecation, were hospitalized longer than Group B patients. Incontinence is another element that speaks high of this technique. In Group A, five patients manifest incontinence in liquid faeces and gases, against one patient of Group B manifesting gas incontinence.

The cause of incontinence in Group A patients is a deformation of the anal canal as a result of the technique known as "syndrome of the keyhole". The incontinence in both groups was rare, at least once a week.

Three months after the intervention five patients of Group A complained of being in pain. Four of them complained of coccygeal pain, not related with defecation. This is an important complication and quite often invalidates the open technique. It is known as the "coccydynia". The posterior anal canal trauma is strongly connected to the coccygeal bone that is formed of some sacral vertebras. The cicatricial connective tissue that fills in the wound has a direct role in damaging the sensitive nerve ends anatomy and in the limitation of the coccygeal bone ability to move. Some studies accuse the termic effect of the electro lancet or the sutures above the anococcygeal ligament, especially in cases of close connections with the anal canal.

Similar researches are random in the medical literature, but we used the V-Y advancement flap technique because we are familiar with it. Our results are comparable and researches have been published. In a research conducted on 33 patients, Brisida $G$ et al and Gingold BS et al, refer to a $100 \%$ coefficient of healing with the Diamond flap technique $(3,4)$. Oh and Zinberg, when using the $\mathrm{C}$ anoplastic technique refers that in 11 out of 12 of the treated patients, the healing percentage is $91 \%(5)$.

As a conclusion, based on our research and many others, we can say that the technique of fixing the intraanal cutaneous skin flap with closed left lateral sphincterotomy, is the selected technique for the treatment of the benign anal stricture of the open posthemorrhoidectomy. It is replacing the anoplastic with posterior sphincterotomy technique which has been used in our clinic for a long time. It is referred that during the execution of the technique there are two key moments: 1) lack of tension in the skin flap and: 2) optimal blood supply in the skin flap. During the open intervention of the hemorrhoidal prolaps, special care should be given to: 1) precise applying and execution of the lateral sphincterotomy and: 2) maximum protection of the anocutaneous area.

\section{References}

[1] Liberman H,Thorson AG. HoW I do it. Anal stenosis. Am J Surg. 2000; 179: 325-329.

[2] Maria G, Brisinda G, Civello IM. Anoplasty for the treatment of anal stenosis. AM J Surg. 1998;175:158160.

[3] Brisida G, Vanella S, Cadeddu F, Marniga G, Mazzeo $\mathrm{P}$, Brandara $\mathrm{F}$ et al. Surgical treatment of anal stenosis. World J Gastroenterol. 2009 April 28; 15 (16): 1921 1928.

[4] Gingold BS, Arvanitis M. Gingold BS, Arvanitis M. Y$\mathrm{V}$ anoplasty for the treatment of anal stricture. Surg Gynecol Obstet. 1986; 162: 241-242.

[5] Oh C, Zimberg J. Anoplastyfor anal stricture. Dis colon Rectum. 1982; 25: 809-810.

[6] Milsom JW, Mazier WP. Clasification and management of postsurgical anal stenosis. Surg Gynecol Obstet. 1986 Jul; 163(1):60-64.

[7] I Selvaxhio, F Cadeeeu, M Grande, G Milito. Surgical management of anal stenosis. BMC Geriatrics

[8] Khubchandani IT. Mucosal advancement anoplasty. Dis Colon Rectum 1985; 28: 194-6.

[9] Musiari JP. Estenosis de ano. Sem Med 1954; 104:8034.

[10]Lucthefeld M. Anal stenosis. Probl Gen Surg 2001; 18:17-23.

[11] Caplin DA, Kodner IJ. Repair of anal stricture and mucosal ectropion by simple flap procedures. Dis Colon Rectum 1986; 29:92-4.

[12] Ramanujan PS, Venkatesh KS. Y-V anoplasty for severe anal stenosis. Contemp Surg 1988; 33:62-8.

[13] Aitola PT,Hiltunen KM, Matikainen MJ. Y-V anoplasty combined with internal sfincterotomy for stenosis of the canal anal. Eur J Surg 1997 Nov; 163(11):839-42.

[14] Sayfan J. Ergotamine-induced anorectal strictures: report of five cases. Dis Colon Rectum 2002; 45:271272. 